\title{
Healthcare utilization and costs among prolactinoma patients: a cross-sectional study and analysis of determinants
}

\author{
Merel van der Meulen ${ }^{1}$ (D) Amir H. Zamanipoor Najafabadi ${ }^{1,2}$. Daniel J. Lobatto ${ }^{1,2}$ (D) Wilbert B. van den Hout ${ }^{3}$ (D) \\ Cornelie D. Andela ${ }^{1}$ D . Ingrid M. Zandbergen ${ }^{1}$ (D) Alberto M. Pereira ${ }^{1}$ (D) Wouter R. van Furth ${ }^{2}$ (D) . \\ Thea P. M. Vliet Vlieland ${ }^{4} \mathbb{D}$. Nienke R. Biermasz ${ }^{1} \mathbb{C}$
}

Accepted: 26 September 2020 / Published online: 6 October 2020

(c) The Author(s) 2020

\begin{abstract}
Purpose Prolactinomas are the most prevalent functioning pituitary adenomas. They affect gonadal function as well as health-related quality of life (HRQoL). This study aimed to report healthcare utilization and costs, including their determinants, for prolactinoma patients.

Methods Cross-sectional study of 116 adult prolactinoma patients in chronic care in a Dutch tertiary referral center. Patients completed four validated questionnaires, assessing healthcare utilization and costs over the previous 12 months (Medical Consumption Questionnaire), disease bother and needs (Leiden Bother and Needs Questionnaire Pituitary), HRQoL (Short Form-36), and self-reported health status (EuroQol 5D). Regression analyses were used to assess associations between disease-related characteristics and healthcare utilization and costs.

Results Mean age was 52.0 years (SD 13.7) and median follow-up was 15.0 years (IQR 7.6-26.1). Patients visited the endocrinologist (86.2\%), general practitioner (37.9\%), and ophthalmologist (25.0\%) most frequently. Psychological care was used by $12.9 \%$ of patients and 5\% were admitted to hospital. Mean annual healthcare costs were $€ 1928$ (SD 3319 ), mainly for pituitary-specific medication (37.6\% of total costs), hospitalization (19.4\%) and specialist care (16.1\%). Determinants for higher healthcare utilization and costs were greater disease bother and needs for support, lower HRQoL, elevated prolactin, and longer disease duration, while tumor size, hypopituitarism and adrenal insufficiency were not significantly associated with healthcare utilization and costs.

Conclusion Healthcare utilization and costs of prolactinoma patients are related to patient-reported HRQoL, bother by disease and needs for support. Therefore, addressing patients' HRQoL and needs is a way forward to improve efficiency of care and patients' health status.
\end{abstract}

Keywords Pituitary adenoma $\cdot$ Prolactinoma $\cdot$ Healthcare utilization $\cdot$ Costs $\cdot$ Health-related quality of life $\cdot$ Value-based healthcare

Electronic supplementary material The online version of this article (https://doi.org/10.1007/s11102-020-01089-1) contains supplementary material, which is available to authorized users.

Merel van der Meulen

m.vandermeulen@lumc.nl

1 Department of Medicine, Division of Endocrinology, Pituitary Center and Center for Endocrine Tumors, Leiden University Medical Center, Leiden, The Netherlands

2 University Neurosurgical Centre Holland, Leiden University Medical Centre, Haaglanden Medical Centre and Haga Teaching Hospital, Leiden, The Hague, The Netherlands
3 Department of Medical Decision Making \& Quality of Care, Leiden University Medical Center, Leiden, The Netherlands

4 Department of Orthopedics, Rehabilitation and Physical Therapy, Leiden University Medical Center, Leiden, The Netherlands 


\section{Introduction}

Prolactinomas are the most prevalent type of pituitary adenoma, comprising up to $66 \%$ of all pituitary adenomas [1]. Beyond the classic hypogonadal symptoms [2], many patients experience cognitive and psychological symptoms [3, 4] that contribute to impairments in healthrelated quality of life (HRQoL) [5]. Dopamine agonists (DA) are the first-line treatment for most patients [6]. While these are highly effective and generally well tolerated [7], side effects may occur [8], most frequently fatigue (30\%), libido changes (28\%), and sleep disorders $(25 \%)$ [9]. Moreover, particularly psychological side effects (e.g., depressive symptoms and behavioral changes) are considered to be underreported [10]. Medical treatment may be temporary, although recent reviews have shown lower remission rates than previously thought (21-36.6\%) [9, 11, 12], suggesting the need for long-term medical treatment $[11,12]$, including ongoing follow-up by endocrinologists and other healthcare professionals [6]. In case of resistance or intolerance to medical therapy, and depending on patient preference, transsphenoidal selective adenomectomy can be considered as alternative treatment option $[6,13]$.

Considering the long-term treatment and follow-up, substantial healthcare utilization and treatment costs of prolactinoma patients can be anticipated. Three studies [14-16] have used simulation models to compare the cost-effectiveness of DA therapy and surgical treatment for prolactinomas, with cost estimates ranging from $\$ 2485$ to $\$ 6042$ per year for medical therapy, and up to $\$ 19,224$ for the first year after surgery (including admission for surgery) [14-16]. In these studies, the costs of surgically treated patients were highest in the first year after surgery, due to the actual intervention and perioperative care, and decreased over time. Consequently, surgery became more cost-effective than DA after five to ten years of follow-up [14]. However, despite the relatively high prevalence of prolactinomas compared to other pituitary adenomas, no empirical studies have reported the annual healthcare utilization and costs in patients with a prolactinoma, whereas such reports, although scarce, do exist for patients with Cushing's disease [17-19], acromegaly [20-23], and non-functioning pituitary adenomas (NFA) [24]. Moreover, insight into the determinants of healthcare utilization and costs of prolactinoma patients is lacking, which might provide information relevant to improve efficiency of care and potentially reduce the costs.

Therefore, this study aimed to report the healthcare utilization, healthcare costs, and their determinants for prolactinoma patients. Microprolactinomas treated with DA were a group of particular interest, as microprolactinomas are the most common type of prolactinomas (around 60\%) [25] with
DA recommended as first-line treatment [6]. We hypothesized that macroprolactinomas were associated with higher healthcare utilization and costs, since these are more often resistant to DA [26, 27], and are more often complicated with visual complaints and hypopituitarism than microprolactinomas [28, 29]. In line with previous findings in patients with an NFA [24], we also expected that patients reporting a greater bother by disease and more needs for support would have higher healthcare utilization and costs. Identification of these disease- or care-related determinants will enhance the understanding of the factors driving healthcare utilization and costs, which can be used to improve efficiency of care and may consequently improve health outcomes of patients treated for a prolactinoma.

\section{Patients and methods}

\section{Study design}

This study presents the data of prolactinoma patients that were collected in a large cross-sectional study assessing healthcare utilization, costs, and work-related disability among pituitary patients [24, 30]. It was performed at the Leiden University Medical Center (LUMC), a tertiary referral center for the diagnosis and treatment of pituitary adenomas in the Netherlands, and was approved by the institutional ethical committee (p12.067).

\section{Patients}

Patients were eligible for participation if they were diagnosed with a prolactinoma (based on symptoms, biochemistry, and MRI), aged $\geq 18$ years, had sufficient Dutch language skills, and had visited the outpatient clinic of our center after December 2014. Patients were excluded if they had not received follow-up care in our center after December 2014, were incapable of completing the questionnaires themselves, or were living abroad. Eligible patients were identified from the hospital registry and invited to participate in this study by their treating physician by means of a letter between September 2016 and March 2017. In case of no response, patients were approached a second time by letter. After informed consent was obtained, patients were enrolled in the study.

\section{Assessments}

Patients completed a set of four validated questionnaires either digitally or on paper. Healthcare usage and costs were assessed with the Medical Consumption Questionnaire of the institute for Medical Technology Assessment (iMTA 
MCQ) [31], perceived bother by disease and needs for support were assessed using the Leiden Bother and Needs Questionnaire for patients with pituitary disease (LBNQPituitary) [32], HRQoL was measured using the Short Form36 (SF-36) [33, 34], and the EuroQol (EQ-5D) [35] was used to assess utility and self-reported health status.

\section{Sociodemographic and clinical characteristics}

Several clinical and sociodemographic characteristics were collected from the medical records, including age, sex, date of diagnosis, tumor size at diagnosis, treatment, and prolactin level at time of study participation. Tumor size was categorized into (1) microprolactinoma $(<10 \mathrm{~mm})$, (2) macroprolactinoma (10-40 mm), (3) giant prolactinoma $(\geq 40 \mathrm{~mm}$ ), and (4) invisible on MRI. The prolactin level at time of study participation (any prolactin level recorded in the patient's medical record between August 2016 and May 2017) was classified as elevated (females $>23.0 \mu \mathrm{g} / \mathrm{L}$, males $>15.0 \mu \mathrm{g} / \mathrm{L}$ ) or normal. Since no data on menopausal status were collected, the percentage of female participants in the postmenopausal age range ( $\geq 50$ years) and premenopausal age range ( $<50$ years) [36] were presented, to give an indication of menopausal status in this cohort.

Self-reported characteristics included marital status, educational level, use of hormone replacement therapy (which was used to determine presence of pituitary dysfunction in any axis), and specifically the use of hydrocortisone replacement (which was used to determine presence of adrenal insufficiency). Level of education was categorized into low, intermediate or high, according to the guidelines of Statistics Netherlands (CBS) [37], that are based on the International Standard Classification of Education: Fields of Training and Education 2013 by UNESCO [38].

\section{Healthcare utilization}

To assess the number of appointments a patient had had with various healthcare professionals in the previous 12 months, the iMTA MCQ [31] was used. We considered appointments with the following healthcare professionals relevant for prolactinoma patients: general practitioner; endocrinologist; neurosurgeon; ophthalmologist; ear, nose and throat (ENT) specialist; neurologist; radiation oncologist; cardiologist; gynecologist; internist; any other medical specialists; occupational physician; psychiatrist/psychologist; physiotherapist; and dietician. Patients were categorized into high $(\geq 3$ visits) or low specialist care utilization ( $<3$ visits), based on the median total number of visits to any medical specialist during the previous 12 months. Moreover, the iMTA MCQ was used to assess medication usage (including frequency and dosage), emergency care (i.e. ambulance rides, visits to the emergency department), hospital admissions (including frequency and duration), and home care (i.e. nursing care, household help).

\section{Perceived bother and needs for support}

The LBNQ-Pituitary is a disease-specific questionnaire, that was developed and validated in a large Dutch sample of patients with pituitary disease in the Netherlands [32]. This questionnaire comprises 26 items covering five subscales: mood problems, negative illness perceptions, sexual functioning problems, physical and cognitive complaints, and social functioning problems. For each subscale and for the total questionnaire, an index score can be calculated (range $0-100$ ) for both bother and needs. Higher scores indicate greater bother by the consequences of the disease and greater needs for support [32].

\section{Health-related quality of life and utility}

The SF-36 is a generic HRQoL questionnaire consisting of 36 items covering eight domains: physical functioning, physical role functioning, bodily pain, general health, vitality, social functioning, emotional role functioning and mental health. These subscales can be used to calculate a physical (PCS) and mental component score (MCS). Both the subscales and the component scores range from 0 to 100 , with higher scores indicating better HRQoL [33].

The EQ-5D (5-level) consists of 5 domains (mobility, self-care, usual activities, pain/discomfort, and anxiety/ depression) with 5 levels (no, slight, moderate, severe, and extreme problems), that are used to calculate utility (range -0.446 to 1 ; EQ-5D index). The EQ-5D also includes a visual analogue scale (VAS), on which patients score their perceived health status (range 0-100), with higher scores indicating a better self-reported health status [35].

\section{Costs}

Healthcare costs were calculated based on the healthcare utilization as reported by the patients. Prices were obtained in accordance with the Dutch manual for costing research [39] and were based on reference prices for 2016, which have been published previously [24]. The presented costs can be converted to dollars using the purchasing power parity provided by the Organization for Economic Co-operation and Development (OECD), which was 0.796 per dollar in 2016 [40]. Medical costs, medication costs, and total costs were presented separately. Medical costs include medical costs of chronic specialist care (including the general practitioner, specialist care, occupational care, mental healthcare, and allied health professionals), medical costs of acute care 
(including ambulance rides, emergency department visits, and hospitalization), and home care costs. Medication costs were presented separately for dopamine agonists (cabergoline, bromocriptine, quinagolide) and hormone replacement therapy (androgel, contraceptives, thyrax, hydrocortisone, genotropin, and desmopressin).

\section{Statistics}

An online survey platform (NET-Q) was used for the questionnaire data entry and all statistical analyses were performed using IBM SPSS 25.0 software (IBM Corp., Armonk, NY). Baseline characteristics, healthcare utilization, and costs were presented using descriptives for the total prolactinoma cohort and were compared between the following main subgroups: (1) patients with a microprolactinoma treated with DA only or not treated at all, (2) patients with a microprolactinoma treated with surgery and/or radiotherapy, (3) patients with a macroprolactinoma treated with DA only or not treated at all, and (4) patients with a macroprolactinoma treated with surgery and/or radiotherapy (Fig. 1). This categorization was chosen based on clinical grounds to gain insight into the healthcare utilization and costs of the 'typical' prolactinoma, the DA-treated microprolactinoma, which may be underrepresented in this academical cohort, since these patients are typically not always referred. These four groups were only compared descriptively for healthcare utilization and costs, as we focused on presenting the absolute costs of these clinically relevant subgroups, rather than statistical differences.

In addition, formal comparisons were made between tumor sizes (micro vs. macro). For the comparisons between tumor sizes, giant prolactinomas were classified as macroprolactinomas, and invisible adenomas were omitted from the analyses ('missing'). Continuous variables were presented as means and standard deviations (SD) or medians with interquartile ranges (IQR) and were compared within the additional categories using the unpaired t-test or Mann-Whitney U test for normal and skewed distributions,

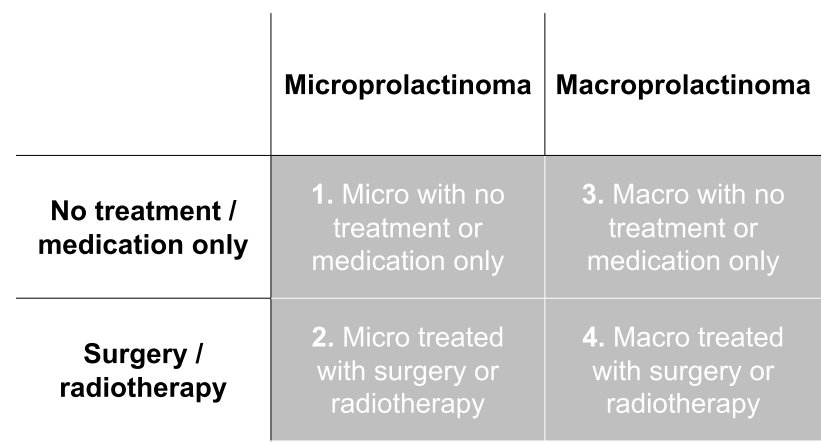

Fig. 1 Visualization of the four main subgroups respectively. Categorical variables were presented as frequencies with percentages and comparisons between tumor sizes were made using Chi-square analyses.

Logistic regression analysis was used to determine associations between specialist care utilization (high/low) and possible health-related contributing factors (clinical characteristics, HRQoL, bother by disease, and needs for support), and associations were expressed as odds ratios (ORs) with 95\% confidence intervals (CIs) and P-values. Associations between overall healthcare costs and the possible contributing factors were determined using linear regression analysis and were presented as regression coefficients $(\beta)$ with corresponding $95 \% \mathrm{CIs}$ and $\mathrm{P}$-values. In order to control for confounding, a separate multivariable regression analysis was performed for the association between each determinant and the outcome, corrected for confounders. In other words, every multivariable regression analysis involved one determinant and included several potential confounders as covariates. Confounders were defined as variables that were associated with both the determinant and the outcome and were not in the causal pathway [41]. Thus, all associations were corrected for age and sex and depending on the determinant also for treatment type or education level. These regression analyses were performed for the total cohort. In addition, for the variables that were significantly different between microprolactinoma and macroprolactinoma patients, the regression analyses were also stratified for tumor size (micro vs. macro).

Perceived bother by disease and needs for support were analyzed using ANCOVA, correcting for age, sex, and education level (Supplement 4).

For all analyses, a P-value $<0.05$ (two-sided) was considered statistically significant. Because of the low number of missing values $(<5 \%)$, complete case analysis was used to handle missing questionnaire data.

\section{Results}

\section{Study population and patient characteristics}

A total of 405 patients with a possible prolactinoma were identified from the hospital registry. After exclusion of patients without a confirmed diagnosis and those not in follow-up care at our institution, 273 patients were invited for participation, 116 (42\%) of whom were enrolled in this study (Fig. 2). The resulting cohort comprised $82(70.7 \%)$ females, 40 of whom $(48.8 \%)$ were in the postmenopausal age range ( 50 years or older). The mean age of the cohort was 52.0 years (SD 13.7, median 53.3, IQR 42.4-61.2) and the median time since diagnosis was 15.0 years (IQR = 7.6-26.1) (Table 1). Hypopituitarism was present in 49 patients (42.2\%), adrenal insufficiency in 19 patients 
Fig. 2 Flowchart of patient inclusion

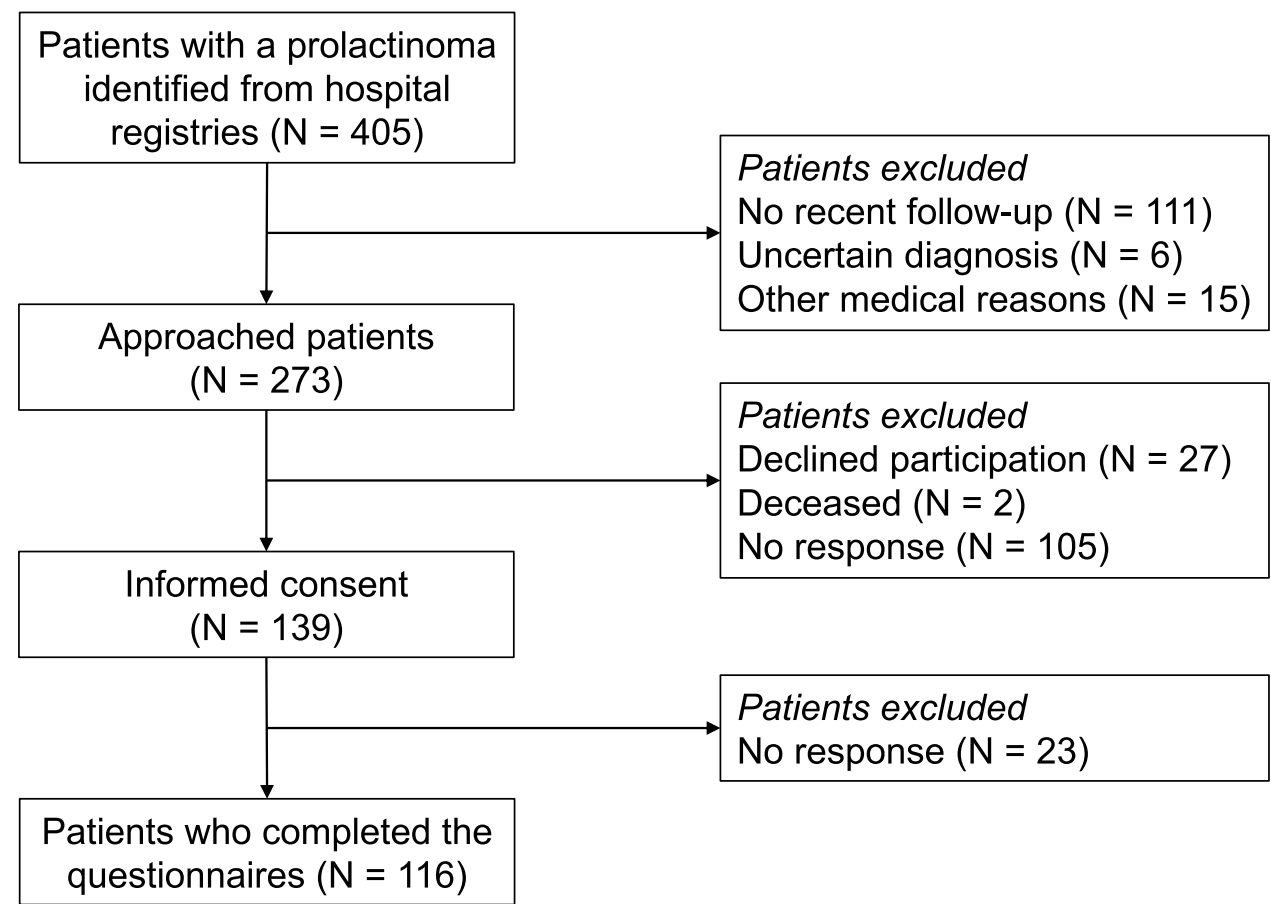

(16.4\%), and 38 patients $(32.8 \%)$ had persistently elevated prolactin levels at the time of study participation. More than half of the patients $(64,55.2 \%)$ were using DA and 28 patients $(24.1 \%)$ had undergone transsphenoidal surgery. Of the 47 patients with a medically treated microprolactinoma (Table 1), 39 (83.0\%) were female, 20 (52.6\%) had elevated prolactin levels, $13(27.7 \%)$ had hypopituitarism, and $3(6.4 \%)$ had adrenal insufficiency. The additional comparisons are presented in Supplement 1.

\section{Healthcare utilization}

\section{Primary care}

The general practitioner had been consulted by 44 patients (37.9\%) in the previous year, and by $19(40.4 \%)$ of the patients with medically treated microprolactinomas (Table 2). Of the other primary healthcare professionals, the physiotherapist had been visited most frequently (total cohort: $n=22,19.0 \%$; medically treated microprolactinoma: $\mathrm{n}=10,21.3 \%$ ). Additional comparisons can be found in Supplement 2 .

\section{Specialist care}

The majority of patients $(n=106,91.4 \%)$ had consulted a medical specialist in the previous year, most commonly the endocrinologist $(n=100,86.2 \%)$, the ophthalmologist $(n=29,25.0 \%)$, and the radiation oncologist $(n=17,14.7 \%)$ (Table 2). Medically treated microprolactinoma patients had visited the endocrinologist $(\mathrm{n}=40,85.1 \%)$, ophthalmologist $(n=11,23.4 \%)$, and internist $(n=6,12.8 \%)$ most often.

\section{Mental healthcare}

Psychological/psychiatric care physicians had been visited by 15 patients $(12.9 \%)$ of the total cohort, and by $9(19.1 \%)$ of the medically treated microprolactinoma patients, which was the highest percentage of the main subgroups (range: 0-19.1\%).

\section{Hospital admissions and emergency care}

In the previous year, 12 patients $(10.3 \%)$ had visited the emergency department at least once (mean 1.3), and 5 patients $(4.3 \%)$ had had an ambulance ride (mean 1) (Table 2). Furthermore, 6 patients $(5.1 \%)$ had been admitted to the hospital at least once, with a mean duration of 8.8 days (range 4-20 days). Of the medically treated microprolactinoma patients, $6(12.8 \%)$ had visited the emergency department, $3(6.4 \%)$ had had an ambulance ride, and $2(4.3 \%)$ had been admitted to the hospital at least once.

\section{Determinants of healthcare utilization}

After correction for relevant confounders, patients with a longer time since diagnosis (OR 0.954, 95\% CI 0.882; 0.976), and patients with a better physical (OR 0.952, 95\% CI 0.915 ; 0.992) and mental (OR 0.953, 95\% CI 0.920; 0.986) HRQoL according to the SF-36 had lower specialist 
Table 1 Characteristics of 116 patients with a prolactinoma, categorized by tumor size and treatment

\begin{tabular}{|c|c|c|c|c|c|}
\hline $\begin{array}{l}\text { Total cohort } \\
(\mathrm{N}=116)^{*}\end{array}$ & $\begin{array}{l}\text { Micro, no treatment } \\
\text { or medication only } \\
(\mathrm{N}=47)^{*}\end{array}$ & $\begin{array}{l}\text { Micro, surgery } \\
\text { and/or radio- } \\
\text { therapy } \\
(\mathrm{N}=6)^{*}\end{array}$ & $\begin{array}{l}\text { Macro, no treatment } \\
\text { or medication only } \\
(\mathrm{N}=37)^{*}\end{array}$ & $\begin{array}{l}\text { Macro, surgery and/ } \\
\text { or radiotherapy } \\
(\mathrm{N}=21)^{*}\end{array}$ & $\begin{array}{l}\text { Missing data of the } \\
\text { total cohort, } \mathrm{N}(\%)\end{array}$ \\
\hline
\end{tabular}

Demographic characteristics

Sex, N (\%)

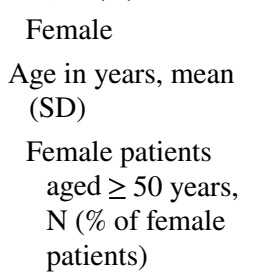

$\begin{array}{llllll}82(70.7) & 39(83.0) & 6(100.0) & 19(51.4) & 14(66.7) & 0 \\ 52.0(13.7) & 51.0(14.5) & 44.8(16.5) & 50.7(12.7) & 56.0(13.2) & 0 \\ 40(48.8) & 17(43.6) & 2(33.3) & 8(42.1) & 9(64.3) & 0 \\ & & & & \\ & & & & \end{array}$

Marital status, $\mathrm{N}$

$(\%)$

Relationship/mar-

87 (75.7)

$34(72.3)$

$5(83.3)$

$29(80.6)$

$16(76.2)$

ried

Education, N (\%)

Low
Intermediate

$30(26.1) \quad 8(17.0)$

$3(50.0)$

$12(33.3)$

4 (19.0)

$27(23.5) \quad 15(31.9) \quad 1(16.7)$

$4(11.1)$

7 (33.3)

High

$24(51.1)$

$2(33.3)$

$20(55.6)$

$10(47.6)$

Disease character-

istics

Time since diagnosis in years,

$15.0(7.6-26.1) \quad 16.6(9.1-26.5)$

$17.0(5.0-27.9)$

$11.0(4.0-16.0)$

$27.0(10.1-35.5)$

0 median (IQR)

Tumor size at diagnosis, $\mathrm{N}(\%)$

Micro (<10 mm)

Macro (10$40 \mathrm{~mm})$

Giant (> 40 mm)

Invisible on MRI

or CT

Treatment, N (\%)

No treatment

Medication only

3 (2.6)

$53(46.5)$

47 (100.0)

$56(49.1)$

0

$2(1.8)$

0

3 (2.6)

0

84 (72.4)

$3(6.4)$

Surgery only

0

44 (93.6)

Radiotherapy only 0

$$
0
$$

0

Medication + sur- 20 (17.2) gery

Medication + radi- $1(0.9)$ otherapy

Surgery + radio- $\quad 4$ (3.4) therapy

Medication + sur- 4 (3.4) gery + radiotherapy

Endocrine status,

$\mathrm{N}(\%)$

Elevated prolactin level

Hypopituitarism $4(42.2)$ 
Table 1 (continued)

\begin{tabular}{|c|c|c|c|c|c|c|}
\hline & $\begin{array}{l}\text { Total cohort } \\
(\mathrm{N}=116)^{*}\end{array}$ & $\begin{array}{l}\text { Micro, no treatment } \\
\text { or medication only } \\
(\mathrm{N}=47)^{*}\end{array}$ & $\begin{array}{l}\text { Micro, surgery } \\
\text { and/or radio- } \\
\text { therapy } \\
(\mathrm{N}=6)^{*}\end{array}$ & $\begin{array}{l}\text { Macro, no treatment } \\
\text { or medication only } \\
(\mathrm{N}=37)^{*}\end{array}$ & $\begin{array}{l}\text { Macro, surgery and/ } \\
\text { or radiotherapy } \\
(\mathrm{N}=21)^{*}\end{array}$ & $\begin{array}{l}\text { Missing data of the } \\
\text { total cohort, } \mathrm{N}(\%)\end{array}$ \\
\hline $\begin{array}{l}\text { Adrenal insuffi- } \\
\text { ciency }\end{array}$ & $1(16.4)$ & $3(6.4)$ & 0 & 7 (18.9) & $7(33.3)$ & \\
\hline \multicolumn{7}{|l|}{$\begin{array}{l}\text { Self-reported health } \\
\text { status }\end{array}$} \\
\hline $\begin{array}{r}\text { EQ-5D score, } \\
\text { mean }(S D)^{\wedge}\end{array}$ & $0.91(0.083)$ & $0.908(0.099)$ & $0.906(0.114)$ & $0.925(0.060)$ & $0.901(0.079)$ & 0 \\
\hline $\begin{array}{l}\text { EQ-5D VAS, } \\
\text { mean }(S D)^{\wedge}\end{array}$ & $75.6(20.3)$ & $73.6(21.8)$ & $71.7(21.1)$ & $78.7(18.4)$ & $76.7(16.1)$ & 0 \\
\hline $\begin{array}{l}\text { SF-36 PCS, mean } \\
(\mathrm{SD})^{\wedge}\end{array}$ & $49.0(9.8)$ & 48.5 (10.6) & $48.4(10.0)$ & $51.3(8.1)$ & $45.3(10.7)$ & 0 \\
\hline $\begin{array}{l}\text { SF-36 MCS, mean } \\
(\mathrm{SD})^{\wedge}\end{array}$ & $48.1(11.7)$ & $47.8(12.2)$ & 46.5 (11.6) & $49.0(11.4)$ & $48.0(12.0)$ & 0 \\
\hline $\begin{array}{l}\text { LBNQ-Pituitary } \\
\text { Bother by dis- } \\
\text { ease, total index } \\
\text { score, mean } \\
(\mathrm{SD}) \dagger\end{array}$ & $15.8(19.1)$ & $14.5(18.5)$ & $26.9(29.2)$ & $13.4(17.3)$ & $19.9(20.5)$ & $5(4.3)$ \\
\hline $\begin{array}{l}\text { LBNQ-Pituitary } \\
\text { needs for sup- } \\
\text { port, total index } \\
\text { score, mean } \\
(\mathrm{SD}) \dagger\end{array}$ & $16.7(20.3)$ & 16. (20.4) & $29.6(33.3)$ & $13.3(17.9)$ & $20.1(19.9)$ & $8(6.9)$ \\
\hline
\end{tabular}

Due to rounding, not all percentages of the categorical variables add up to $100 \%$

$N$ number, $S D$ standard deviation, $I Q R$ interquartile range, $R T$ radiotherapy, $V A S$ visual analogue scale, $E Q-5 D$ EuroQoL, $S F-36$ Short Form-36, $L B N Q$-Pituitary Leiden Bother and Needs Questionnaire for patients with pituitary disease, MCS mental component score, $P C S$ physical component score

*Percentages are calculated over the number of patients for whom data were available per variable

${ }^{\wedge}$ Higher scores indicate better HRQoL

${ }^{\dagger}$ Lower scores indicate lower disease burden

care utilization. Conversely, patients with elevated prolactin levels (OR 2.661, 95\% CI 1.112; 6.366), greater bother by disease (OR $1.053,95 \%$ CI $1.024 ; 1.082$ ) or greater needs for support (LBNQ-Pituitary) (OR 1.057, 95\% CI 1.028; 1.087) had a higher specialist care utilization (Table 4). When stratified for tumor size, elevated prolactin levels were a significant determinant of healthcare utilization only in microprolactinoma patients (OR 6.318, 95\% CI 1.429; 27.934). Overall, tumor size, prolactinoma treatment, hypopituitarism, and adrenal insufficiency were not significantly associated with healthcare utilization.

\section{Costs}

The mean annual healthcare costs of prolactinoma patients who had used healthcare in the previous year were $€ 1928$ $(\mathrm{SD}=3319)$ (Table 3). Pituitary-specific medication constituted the largest expenditure (37.6\% of all costs), followed by hospitalization (19.4\%) and specialist care
(16.1\%) (Fig. 3). Medication costs were especially high for surgically treated macroprolactinoma patients (€2506), compared to surgically treated microprolactinoma patients $(€ 20)$, and medically treated microprolactinoma ( $€ 552)$ and macroprolactinoma patients (€764). The main contributor to these high medication costs were the costs for hormone replacement therapy, which were significantly higher for patients with a macroprolactinoma $(€ 1595)$ compared to patients with a microprolactinoma $(€ 174, \mathrm{P}<0.001)$ (Supplement 3). Furthermore, medical costs of chronic specialist care and acute care (excluding home care, since this large expenditure was only used by two patients and was probably not prolactinoma-related) were almost $50 \%$ higher for patients with microprolactinomas $(€ 1242)$ compared to macroprolactinomas ( $€ 882)$, although this was not statistically significant $(\mathrm{P}=0.441)$ (Supplement 3$)$. 


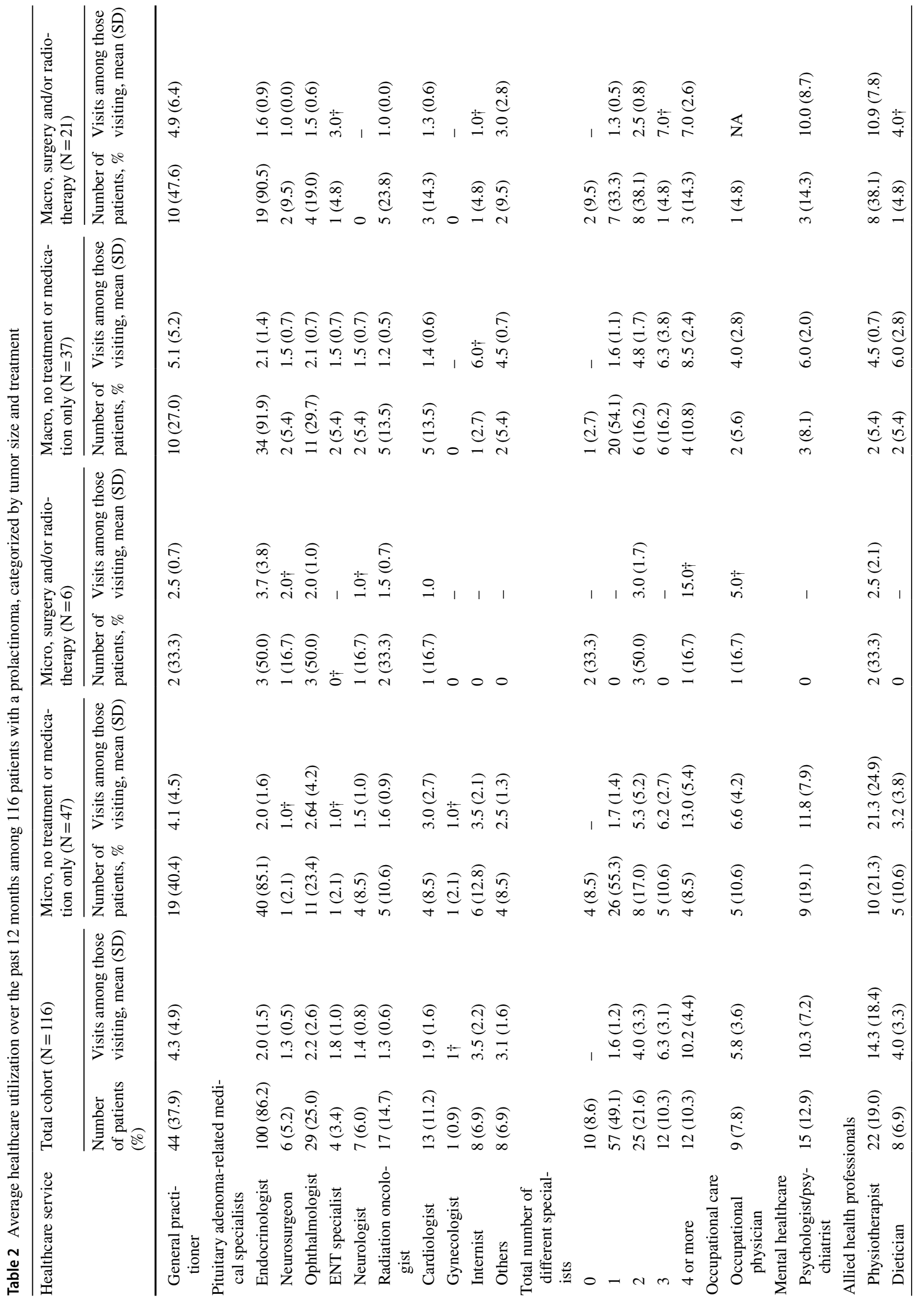


Pituitary (2021) 24:79-95

87

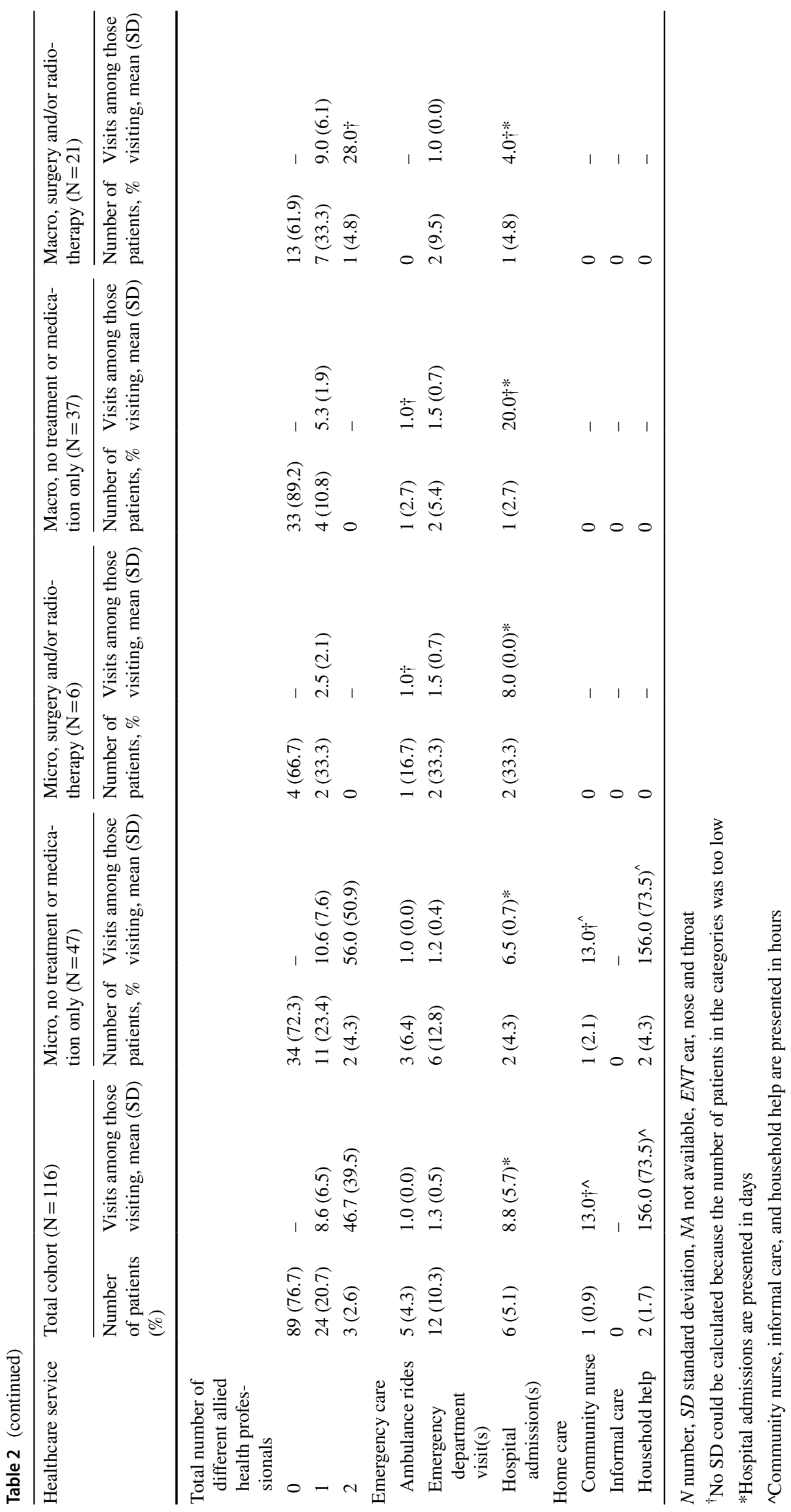

Springer 


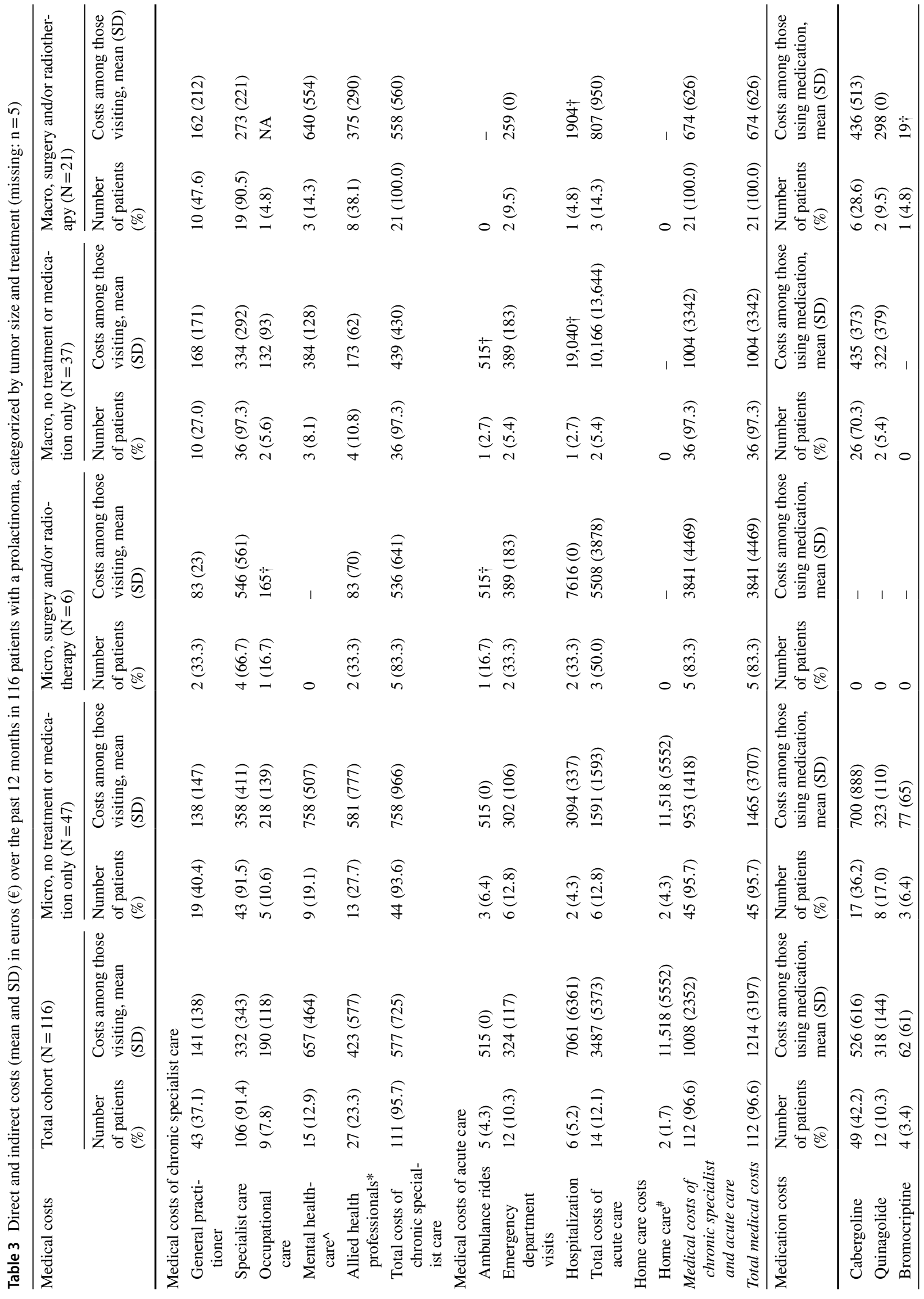




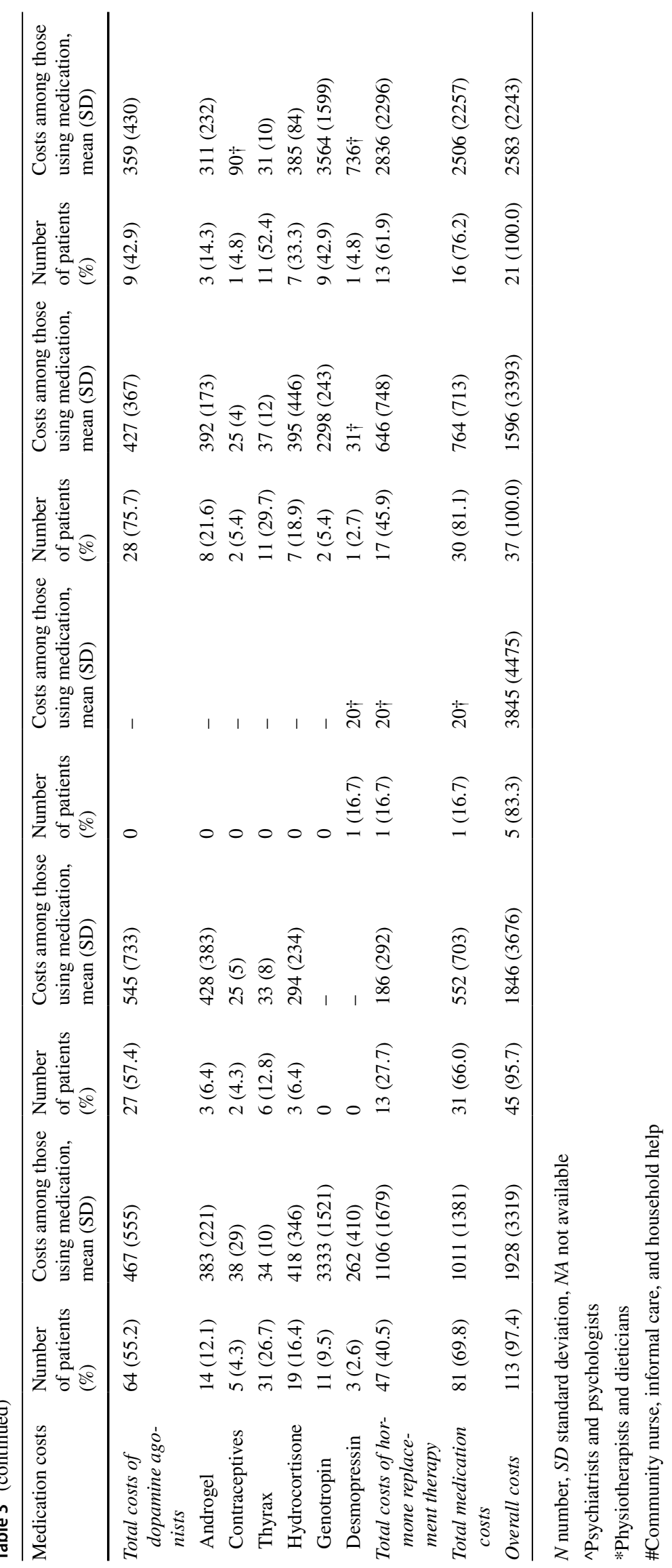



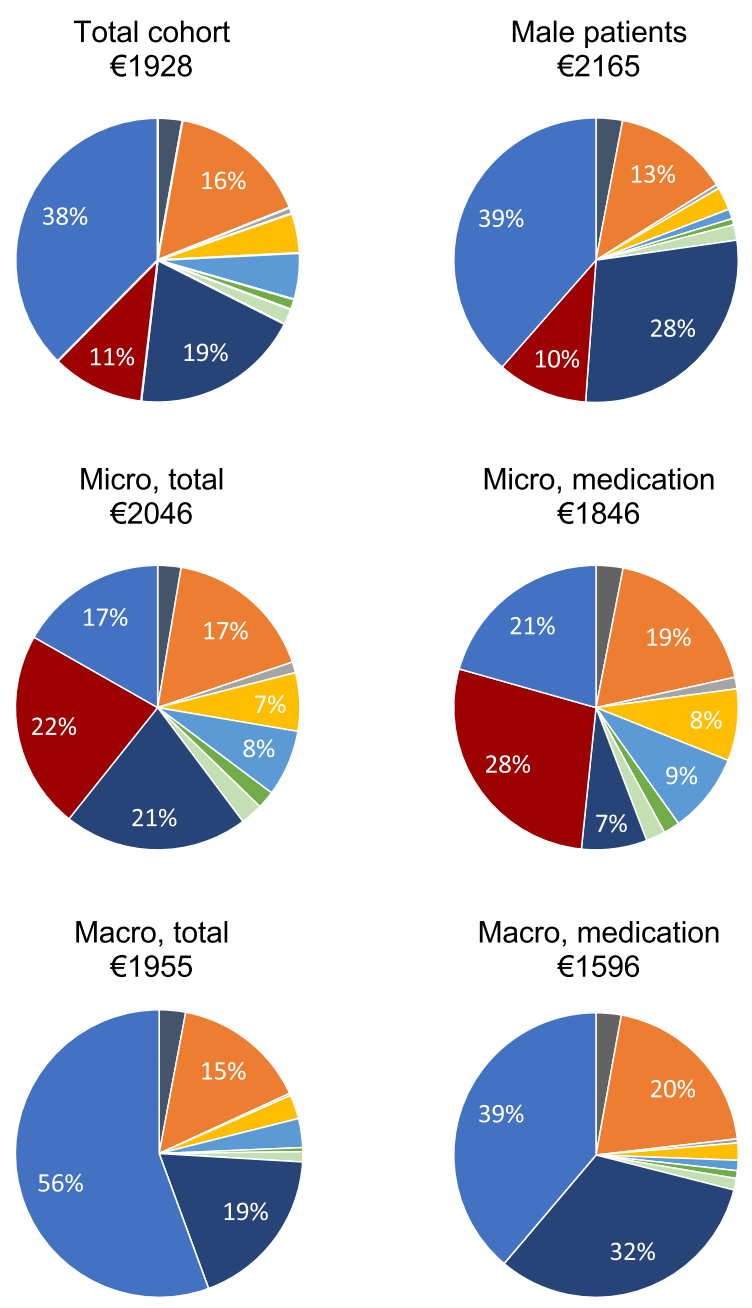

Fig. 3 Pie charts showing the proportions of total medical costs for the different expenditures, categorized by tumor size and treatment, and by sex. Micro (microprolactinoma), macro (macroprolactinoma),

\section{Determinants of increased costs}

Healthcare costs were not significantly associated with clinical determinants (Table 4). Patients with a better overall physical HRQoL (SF-36) $(\beta=-159,95 \%$ CI $-216 ;-102)$ and a higher self-reported health status (EQ VAS) $(\beta=-50,95 \%$ CI - 79; - 20) had significantly lower healthcare costs. In contrast, healthcare costs were significantly higher for patients with greater bother by disease $(\beta=64,95 \%$ CI $31 ; 97)$ and greater needs for support (LBNQ-Pituitary) $(\beta=59,95 \% \mathrm{CI}$ 28; 91). In the analysis stratified for tumor size, hypopituitarism was associated with higher costs only in macroprolactinoma patients ( $\beta=1914,95 \%$ CI 197; 3631).
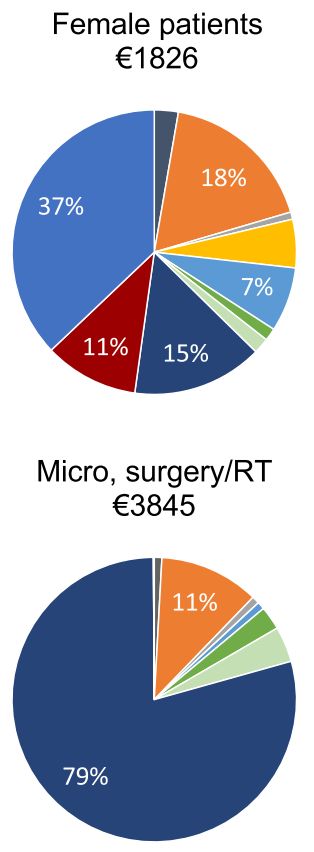

- General practitioner

- Specialist care

- Occupational care

Mental healthcare

- Allied health professionals

- Ambulance rides

Emergency room visits

- Hospitalization

- Home care

Macro, surgery/RT $€ 2583$

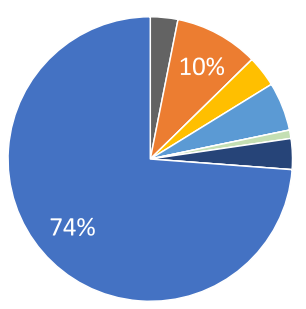

- Medication

RT (radiotherapy). Allied health professionals include physiotherapists and dieticians. Percentages are shown for categories contributing more than $5 \%$ to the total medical costs

\section{Discussion}

Although an increasing number of studies has shown persistent impairments in HRQoL in patients with prolactinomas and other pituitary adenomas [5], little is known about the long-term pituitary disease burden in terms of healthcare utilization and costs. The present study provides insight into the healthcare utilization and costs of prolactinoma patients and shows that the endocrinologist is visited most frequently, reflecting the chronic endocrine care needed for this condition, while other specialists are consulted less frequently. Pituitary-specific medication constitutes the main expenditure. Contrary to our hypothesis, prolactinomarelated healthcare utilization and costs were overall not significantly higher for patients with a macroprolactinoma, except for medication costs. As expected, worse HRQoL, greater bother by disease and greater needs for support were 
Table 4 Logistic/linear regression analysis per determinant for medical specialist utilization and costs among patients with a prolactinoma $(\mathrm{N}=116)$

\begin{tabular}{|c|c|c|c|c|c|c|}
\hline \multirow[t]{2}{*}{ Determinant } & \multicolumn{3}{|c|}{$\begin{array}{l}\text { High specialist utilization (adjusted for } \\
\text { demographics*) }\end{array}$} & \multicolumn{3}{|c|}{$\begin{array}{l}\text { Healthcare costs (adjusted for demograph- } \\
\text { ics*) }\end{array}$} \\
\hline & OR & $95 \% \mathrm{CI}$ & P-value & $\beta$ & $95 \% \mathrm{CI}$ & P-value \\
\hline \multicolumn{7}{|l|}{ Clinical determinants } \\
\hline Time since diagnosis ${ }^{1,2}$ & 0.954 & $0.913 ; 0.996$ & $\mathbf{0 . 0 3 3}$ & 21 & $-45 ; 86$ & 0.536 \\
\hline \multicolumn{7}{|c|}{ Tumor size at diagnosis (reference: Micro) $)^{1,2}$} \\
\hline Macro (including Giant) & 1.033 & $0.456 ; 2.298$ & 0.936 & -93 & $-1431 ; 1245$ & 0.891 \\
\hline \multicolumn{7}{|l|}{ Treatment (reference: No treatment) ${ }^{1,2}$} \\
\hline Medication only & 1.318 & $0.109 ; 16.007$ & 0.828 & 164 & $-3838 ; 4165$ & 0.936 \\
\hline Medication + surgery & 0.774 & $0.055 ; 10.800$ & 0.849 & 1202 & $-2998 ; 5403$ & 0.572 \\
\hline Medication + radiotherapy & 0.000 & $0.000 ;-$ & 1.000 & 2614 & $-5075 ; 10,302$ & 0.502 \\
\hline Surgery + radiotherapy & 1.996 & $0.090 ; 44.289$ & 0.662 & 530 & $-4548 ; 5607$ & 0.836 \\
\hline Medication + surgery + radiotherapy & 0.530 & $0.019 ; 14.952$ & 0.709 & 905 & $-4221 ; 6031$ & 0.727 \\
\hline \multicolumn{7}{|c|}{ Endocrine status (reference: Normal/no deficits) $)^{1,2,3}$} \\
\hline Elevated prolactin level & 2.661 & $1.112 ; 6.366$ & 0.028 & -720 & $-1870 ; 431$ & 0.217 \\
\hline Hypopituitarism & 1.086 & $0.488 ; 2.418$ & 0.840 & 1093 & $-261 ; 2447$ & 0.112 \\
\hline Adrenal insufficiency & 1.217 & $0.405 ; 3.657$ & 0.726 & 754 & $-1135 ; 2642$ & 0.431 \\
\hline \multirow{2}{*}{\multicolumn{7}{|c|}{$\begin{array}{l}\text { HRQoL, bother by disease and needs for support } \\
\text { SF- } 36^{1,2,4}\end{array}$}} \\
\hline & & & & & & \\
\hline Mental component scale & 0.954 & $0.921 ; 0.989$ & 0.010 & -43 & $-97 ; 11$ & 0.115 \\
\hline Physical component scale & 0.949 & $0.911 ; 0.989$ & 0.012 & -159 & $-216 ;-102$ & $<0.001$ \\
\hline \multicolumn{7}{|l|}{ EQ-5D $D^{1,2,4}$} \\
\hline EQ VAS (scale 0-100) & 0.991 & $0.972 ; 1.009$ & 0.319 & $-\mathbf{5 0}$ & $-79 ;-20$ & 0.001 \\
\hline \multicolumn{7}{|l|}{ Bother by disease (LBNQ-Pituitary) $)^{1,2,4}$} \\
\hline Physical \& cognitive complaints & 1.040 & $1.019 ; 1.062$ & $<0.001$ & 59 & $33 ; 84$ & $<0.001$ \\
\hline Mood & 1.042 & $1.019 ; 1.064$ & $<0.001$ & 44 & $18 ; 69$ & 0.005 \\
\hline Negative illness perceptions & 1.053 & $1.023 ; 1.085$ & 0.001 & 31 & $-5 ; 68$ & 0.086 \\
\hline Sexual functioning & 1.020 & $1.002 ; 1.039$ & 0.032 & 52 & $26 ; 79$ & $<0.001$ \\
\hline Social functioning & 1.038 & $1.013 ; 1.064$ & 0.003 & 36 & $8 ; 65$ & 0.013 \\
\hline Total index score & 1.054 & $1.025 ; 1.085$ & $<0.001$ & 64 & 31; 97 & $<0.001$ \\
\hline \multicolumn{7}{|l|}{ Needs for support (LBNQ-Pituitary) $)^{1,2,4}$} \\
\hline Physical \& cognitive complaints & 1.042 & $1.021 ; 1.064$ & $<0.001$ & 54 & $30 ; 78$ & $<0.001$ \\
\hline Mood & 1.036 & $1.017 ; 1.055$ & $<0.001$ & 35 & $12 ; 59$ & 0.003 \\
\hline Negative illness perceptions & 1.047 & $1.021 ; 1.073$ & $<0.001$ & 21 & $-8 ; 50$ & 0.152 \\
\hline Sexual functioning & 1.017 & $1.001 ; 1.034$ & 0.039 & 50 & 27; 72 & $<0.001$ \\
\hline Social functioning & 1.042 & $1.015 ; 1.069$ & 0.002 & 40 & $11 ; 68$ & 0.007 \\
\hline Total index score & 1.058 & $1.028 ; 1.088$ & $<0.001$ & 59 & $28 ; 91$ & $<0.001$ \\
\hline
\end{tabular}

Bold $(\mathrm{P}<0.05)$, OR odds ratio, CI confidence interval, HRQoL Health related-quality of life, $S F-36$ Short Form-36, EQ-5D EuroQoL, $L B N Q$ Pituitary Leiden Bother and Needs Questionnaire for patients with pituitary disease

SF-36, EQ-5D: higher scores indicate better HRQoL. LBNQ-Pituitary: lower scores indicate lower bother by disease or needs for support *1,2,3,4 Adjusted for age (1), sex (2), treatment (3), education level (4)

significantly associated with higher healthcare utilization and costs. Besides elevated prolactin levels, no other clinical factors showed significant associations. This accentuates the relevance of attention for HRQoL and patient-reported bother and needs in pituitary care, which can be facilitated by patient-reported outcome measures (PROMs) such as the LBNQ-Pituitary [32]. Furthermore, these findings suggest that interventions aiming to improve HRQoL, such as patient education, psychosocial support, and rehabilitation programs [42-46], can be helpful in reducing healthcare utilization and potentially costs in other areas of healthcare.

No previous empirical studies were available for comparison of healthcare utilization and costs for patients with a prolactinoma. However, three cost simulation studies 
[14-16] estimated higher annual costs $(\$ 2485$ to $\$ 6042$ for medical therapy, and up to $\$ 19,224$ for the first year following surgery) compared to the costs observed in our population. Compared to other types of pituitary adenomas, healthcare costs of prolactinomas appear to be lower, as previous studies reported costs ranging between $\$ 26,269$ and $\$ 34,992$ for Cushing's disease, between $€ 9200$ and $€ 32,807$ for acromegaly, and between $€ 3040$ and $\$ 13,708$ for patients with an NFA [17-24]. It is important to note that international comparisons between healthcare costs are hampered by variations in healthcare costs between countries, with especially high healthcare costs in the USA [47], although the few studies performed in European countries showed higher healthcare costs [21, 23, 24] than our study, too. Besides differences in pharmaceutical costs, healthcare expenditures may also be affected by differences between healthcare systems, specifically with regards to the role of general practitioners who serve as gatekeepers for specialist care in the Netherlands [48, 49]. Compared to the general Dutch population, with average yearly healthcare costs of $€ 5129$ per capita in 2017 [50], the costs for the prolactinoma patients in our study appear to be lower as well. However, the value of this comparison is limited since we mainly assessed prolactinoma-related costs in our study, while it is likely that patients also had healthcare costs besides these prolactinoma-related costs.

Moreover, we found a lower healthcare utilization in prolactinoma patients than previously reported in other types of pituitary adenoma, as shown by a lower frequency of visits to medical specialists (91.4\% vs. 94-99\%), hospitalizations (5.1\% vs. $9.5-38.4 \%$ ), and ER visits (10.3\% vs. $11.4-34.2 \%)$ [17-24]. Compared to the general Dutch population, visits to general practitioners and physiotherapists and hospital admissions reported by prolactinoma patients are also lower [51], but this comparison is subject to the same limitations as described above. Interestingly, however, we found a higher frequency of prolactinoma-related mental healthcare utilization than reported for the general population (9.1\%), which was especially remarkable for the 'typical' microprolactinoma (19.1\%). Furthermore, prolactinoma patients visited medical specialists more frequently $(91.4 \%)$ than the general population (39.4\%) [51], which is in line with expectations because standard care for most prolactinoma patients in our center involves a one- to three-yearly visit to the endocrinologist, and other medical specialists if needed.

The results of the present study were most comparable to our recent healthcare utilization study in patients with an NFA from the same Dutch tertiary referral center, in which we reported total annual healthcare costs of $€ 3040,13.8 \%$ hospitalizations, $6 \%$ ambulance rides, and $11.4 \%$ ER visits [24]. In accordance with our findings in prolactinoma patients, patients with an NFA visited the endocrinologist (94.6\%), ophthalmologist (58.4\%), and general practitioner
(51.5\%) most often [24]. While most other studies did not specify the frequency of visits per healthcare provider, one study in patients with acromegaly [20] reported that primary care and endocrine specialist care were used most frequently.

This is one of the few studies $[20,24]$ assessing the determinants of healthcare utilization and costs of pituitary adenomas. In contrast to a study in patients with acromegaly that reported that female sex, younger age, hypopituitarism, and a higher number of comorbidities were associated with higher healthcare costs and utilization [20], we only identified elevated prolactin levels as clinical determinant of healthcare utilization, and we did not identify any clinical determinants of healthcare costs. In this cohort, prolactin levels had not completely normalized in almost a third of the patients. Although marginally elevated prolactin levels do not necessary affect patients negatively and may even be beneficial for metabolism [52], we show that elevated prolactin levels are associated with higher healthcare utilization in patients with a prolactinoma. The exact reasons for the elevated prolactin levels in this cohort are unknown, although it is likely that a combination of multiple factors has played a role, including non-adherence, side effects, resistance, and a lack of clinical indication for dopamine agonist treatment. Mainly patients who have started medical therapy recently and patients with resistance to medication have considerably elevated prolactin levels and require more intensive monitoring, which may explain the higher healthcare utilization for patients with elevated prolactin levels.

It may be surprising that no other clinical variables, such as hypopituitarism and adrenal insufficiency, were significantly associated with healthcare utilization and costs. Subgroup analysis revealed that even in macroprolactinoma patients, who suffered most from these complications (Supplement 1), no consistent associations were present. However, we did observe that medication costs were higher for patients with a macroprolactinoma, while medical costs were lower, resulting in similar costs for micro- and macroprolactinomas.

Our finding that lower self-reported HRQoL and greater bother by disease and needs for support were associated with higher healthcare utilization and costs is in line with our previous study in patients with an NFA [24]. Although much remains to be elucidated, it is likely that impairment in HRQoL in patients treated for a prolactinoma is caused by an interplay of symptoms of hyperprolactinemia, side effects of medical therapy, and possibly consequences of hypopituitarism [5]. Moreover, psychosocial interventions such as self-management and educational programs have proven beneficial for pituitary patients' HRQoL [42-44]. Although these interventions will require financial investment, the relation between HRQoL and healthcare utilization and costs found in NFA and prolactinoma patients suggests that these interventions may not only improve HRQoL but may 
thereby also reduce costs in other areas of healthcare on the long term. Therefore, more research is needed to identify treatable factors that contribute to the reduced HRQoL in this population, and to develop specific interventions aiming to improve HRQoL.

\section{Strengths and limitations}

This is the first study to report healthcare utilization and costs and their determinants for prolactinoma patients. A clear strength of this study is the fact that self-reported data were used, which is considered the most preferable method for the measurement of healthcare costs [53]. However, the self-reported data also pose a limitation to this study, as patients may not be familiar with medical terminology, such as names of healthcare professionals, and may make mistakes, for example when reporting dosages of medication. Furthermore, while the questionnaire explicitly asked for only prolactinoma-related visits to healthcare professionals and home care, some patients may have overlooked that, since two patients reported high home care utilization which is unlikely to be directly related to their prolactinoma. We were also unable to distinguish between prolactinomarelated and -unrelated hospital admissions and emergency care, as this distinction was not made by the questionnaire that was used. Another limitation is the fact that only pituitary-specific medication was recorded in this study, which may have resulted in an underestimation of total medication costs. Moreover, despite the fact that comorbidities can have important impact on HRQoL [54], no comorbidities were documented in this study and we were therefore unable to analyze comorbidity-specific impact on patients' HRQoL. Furthermore, while it would have provided valuable information, we decided not to consider giant prolactinomas and invasive prolactinomas separately, since the numbers of patients in these groups were too small to provide representative results. Also, the cross-sectional study design carries a risk of reverse causality in the interpretation of the data, and, as mentioned previously, the international variation in healthcare costs limits the international comparability of our results. Finally, the generalizability of our results may be limited by the single-center design and the fact that only patients who had visited the outpatient endocrine clinic of our tertiary referral center in the past two years were invited for participation. The resulting academic cohort comprises a relatively high percentage of macroprolactinomas, which are more often resistant to medication $[26,27]$ and were more often surgically treated (Supplement 1 ) than microprolactinomas. The fact that only $42 \%$ of the invited participants provided informed consent may have strengthened this selection bias, and we may have missed some prolactinoma patients who were treated primarily by the gynecologist and had not been referred to the endocrinologist. Although we stratified the analyses for tumor size and treatment in order to gain insight into the common DA-treated microprolactinoma patients, these patients are still a selected cohort treated in a tertiary referral center and are consequently not entirely representative for the general prolactinoma population. New studies in less selected, more representative cohorts of prolactinoma patients are therefore needed to gain insight into the costs of the different treatment strategies for prolactinomas.

\section{Conclusion}

Healthcare utilization and costs of patients treated for a prolactinoma are mainly associated with HRQoL, bother by disease, and needs for support. These results accentuate the need for attention for HRQoL in this population and for a multidisciplinary approach to pituitary care, as well as interventions to improve patients' self-perceived health status in the chronic phase of prolactinoma treatment.

Acknowledgements We would like to thank Anath N.V. Steffens for her assistance with the collection of the data.

Author contributions AMP, DJL, NRB, TPMVV, and WBH contributed to the study conception and design. Data collection was performed by DJL. Data analysis was performed by MM and DJL. The first draft of the manuscript was written by MM and AHZN and all authors commented on previous versions of the manuscript. All authors read, commented, adjusted, and approved the final manuscript.

Funding This study was performed with financial support of the MD/ $\mathrm{PhD}$ grant of the Leiden University Medical Center, and of an ASPIRE young investigator research grant (Grant Number WI219567, Pfizer, New York, USA). Pfizer, however, had no involvement in the project; the views expressed in this paper are those of the authors only and are not attributable to Pfizer.

Data availability Data requests can be directed to DJL: D.J.Lobatto@ lumc.nl.

\section{Compliance with ethical standards}

Conflict of interest The authors declare that they have no conflict of interest.

Ethical approval All procedures performed in studies involving human participants were in accordance with the ethical standards of the institutional and/or national research committee and with the 1964 Helsinki declaration and its later amendments or comparable ethical standards. This study was approved by the Medical Ethical Committee of the Leiden University Medical Center (No. p12.067).

Informed consent Informed consent was obtained from all individual participants included in the study.

Open Access This article is licensed under a Creative Commons Attribution 4.0 International License, which permits use, sharing, 
adaptation, distribution and reproduction in any medium or format, as long as you give appropriate credit to the original author(s) and the source, provide a link to the Creative Commons licence, and indicate if changes were made. The images or other third party material in this article are included in the article's Creative Commons licence, unless indicated otherwise in a credit line to the material. If material is not included in the article's Creative Commons licence and your intended use is not permitted by statutory regulation or exceeds the permitted use, you will need to obtain permission directly from the copyright holder. To view a copy of this licence, visit http://creativecommons .org/licenses/by/4.0/.

\section{References}

1. Karavitaki N (2012) Prevalence and incidence of pituitary adenomas. Ann Endocrinol (Paris) 73(2):79-80. https://doi. org/10.1016/j.ando.2012.03.039

2. Samperi I, Lithgow K, Karavitaki N (2019) Hyperprolactinaemia. J Clin Med. https://doi.org/10.3390/jcm8122203

3. Bala A, Łojek E, Marchel A (2016) Cognitive functioning of patients with a PRL-secreting pituitary adenoma: a preliminary report. Neurology 86(8):731-734. https://doi.org/10.1212/ wnl.0000000000002252

4. Reavley A, Fisher AD, Owen D, Creed FH, Davis JR (1997) Psychological distress in patients with hyperprolactinaemia. Clin Endocrinol (Oxf) 47(3):343-348. https://doi.org/10.104 6/j.1365-2265.1997.2701073.x

5. Andela CD, Scharloo M, Pereira AM, Kaptein AA, Biermasz NR (2015) Quality of life (QoL) impairments in patients with a pituitary adenoma: a systematic review of QoL studies. Pituitary 18(5):752-776. https://doi.org/10.1007/s11102-015-0636-7

6. Melmed S, Casanueva FF, Hoffman AR, Kleinberg DL, Montori VM, Schlechte JA, Wass JA (2011) Diagnosis and treatment of hyperprolactinemia: an endocrine society clinical practice guideline. J Clin Endocrinol Metab 96(2):273-288. https://doi. org/10.1210/jc.2010-1692

7. Webster J, Piscitelli G, Polli A, Ferrari CI, Ismail I, Scanlon MF (1994) A comparison of cabergoline and bromocriptine in the treatment of hyperprolactinemic amenorrhea. Cabergoline Comparative Study Group. N Engl J Med 331(14):904-909. https://doi.org/10.1056/nejm199410063311403

8. Colao A, Di Sarno A, Guerra E, De Leo M, Mentone A, Lombardi G (2006) Drug insight: cabergoline and bromocriptine in the treatment of hyperprolactinemia in men and women. Nat Clin Pract Endocrinol Metab 2(4):200-210. https://doi. org/10.1038/ncpendmet0160

9. Zamanipoor Najafabadi AH, Zandbergen IM, de Vries F, Broersen LHA, van den Akker-van Marle ME, Pereira AM, Peul WC, Dekkers OM, van Furth WR, Biermasz NR (2020) Surgery as a viable alternative first-line treatment for prolactinoma patients: a systematic review and meta-analysis. J Clin Endocrinol Metab 105(3):e32-41. https://doi.org/10.1210/clinem/ dgz144

10. Ioachimescu AG, Fleseriu M, Hoffman AR, Vaughan Iii TB, Katznelson L (2019) Psychological effects of dopamine agonist treatment in patients with hyperprolactinemia and prolactinsecreting adenomas. Eur J Endocrinol 180(1):31-40. https://doi. org/10.1530/eje-18-0682

11. Dekkers OM, Lagro J, Burman P, Jørgensen JO, Romijn JA, Pereira AM (2010) Recurrence of hyperprolactinemia after withdrawal of dopamine agonists: systematic review and meta-analysis. J Clin Endocrinol Metab 95(1):43-51. https://doi.org/10.1210/ jc. $2009-1238$
12. Xia MY, Lou XH, Lin SJ, Wu ZB (2018) Optimal timing of dopamine agonist withdrawal in patients with hyperprolactinemia: a systematic review and meta-analysis. Endocrine 59(1):50-61. https://doi.org/10.1007/s12020-017-1444-9

13. Honegger J, Nasi-Kordhishti I, Aboutaha N, Giese S (2020) Surgery for prolactinomas: a better choice? Pituitary 23(1):45-51. https://doi.org/10.1007/s11102-019-01016-z

14. Jethwa PR, Patel TD, Hajart AF, Eloy JA, Couldwell WT, Liu JK (2016) Cost-Effectiveness analysis of microscopic and endoscopic transsphenoidal surgery versus medical therapy in the management of microprolactinoma in the United States. World Neurosurg 87:65-76. https://doi.org/10.1016/j.wneu.2015.10.090

15. Zygourakis CC, Imber BS, Chen R, Han SJ, Blevins L, Molinaro A, Kahn JG, Aghi MK (2017) Cost-effectiveness analysis of surgical versus medical treatment of prolactinomas. J Neurol Surg B 78(2):125-131. https://doi.org/10.1055/s-0036-1592193

16. Duan L, Yan H, Huang M, Zhang Y, Gu F (2017) An economic analysis of bromocriptine versus trans-sphenoidal surgery for the treatment of prolactinoma. J Craniofac Surg 28(4):1046-1051. https://doi.org/10.1097/scs.0000000000003456

17. Broder MS, Neary MP, Chang E, Ludlam WH (2015) Incremental healthcare resource utilization and costs in US patients with Cushing's disease compared with diabetes mellitus and population controls. Pituitary 18(6):796-802. https://doi.org/10.1007/s1110 2-015-0654-5

18. Broder MS, Neary MP, Chang E, Cherepanov D, Ludlam WH (2015) Burden of illness, annual healthcare utilization, and costs associated with commercially insured patients with Cushing disease in the United States. Endocr Pract 21(1):77-86. https://doi. org/10.4158/ep14126.Or

19. Swearingen B, Wu N, Chen SY, Pulgar S, Biller BM (2011) Health care resource use and costs among patients with cushing disease. Endocr Pract 17(5):681-690. https://doi.org/10.4158/ ep10368.Or

20. Broder MS, Neary MP, Chang E, Cherepanov D, Katznelson L (2014) Treatments, complications, and healthcare utilization associated with acromegaly: a study in two large United States databases. Pituitary 17(4):333-341. https://doi.org/10.1007/s1110 2-013-0506-0

21. Didoni G, Grottol S, Gasco V, Battistini M, Ferone D, Giusti M, Ragazzoni F, Ruffo P, Ghigo E, Minuto F (2004) Cost-ofillness study in acromegalic patients in Italy. J Endocrinol Invest 27(11):1034-1039. https://doi.org/10.1007/bf03345306

22. Placzek H, Xu Y, Mu Y, Begelman SM, Fisher M (2015) Clinical and economic burden of commercially insured patients with acromegaly in the United States: a retrospective analysis. J Manag Care Spec Pharm 21(12):1106-1112. https://doi.org/10.18553/ jmcp.2015.21.12.1106

23. Lesén E, Granfeldt D, Houchard A, Dinet J, Berthon A, Olsson DS, Björholt I, Johannsson G (2017) Comorbidities, treatment patterns and cost-of-illness of acromegaly in Sweden: a registerlinkage population-based study. Eur J Endocrinol 176(2):203-212. https://doi.org/10.1530/eje-16-0623

24. Lobatto DJ, van den Hout WB, Zamanipoor Najafabadi AH, Steffens ANV, Andela CD, Pereira AM, Peul WC, van Furth WR, Biermasz NR, Vliet Vlieland TPM (2019) Healthcare utilization and costs among patients with non-functioning pituitary adenomas. Endocrine 64(2):330-340. https://doi.org/10.1007/s1202 0-019-01847-7

25. Soto-Pedre E, Newey PJ, Bevan JS, Greig N, Leese GP (2017) The epidemiology of hyperprolactinaemia over 20 years in the Tayside region of Scotland: the prolactin epidemiology, audit and research study (PROLEARS). Clin Endocrinol (Oxf) 86(1):60-67. https:// doi.org/10.1111/cen.13156

26. Di Sarno A, Landi ML, Cappabianca P, Di Salle F, Rossi FW, Pivonello R, Di Somma C, Faggiano A, Lombardi G, Colao A 
(2001) Resistance to cabergoline as compared with bromocriptine in hyperprolactinemia: prevalence, clinical definition, and therapeutic strategy. J Clin Endocrinol Metab 86(11):5256-5261. https ://doi.org/10.1210/jcem.86.11.8054

27. Ono M, Miki N, Kawamata T, Makino R, Amano K, Seki T, Kubo O, Hori T, Takano K (2008) Prospective study of high-dose cabergoline treatment of prolactinomas in 150 patients. J Clin Endocrinol Metab 93(12):4721-4727. https://doi.org/10.1210/ jc.2007-2758

28. Colao A, Vitale G, Cappabianca P, Briganti F, Ciccarelli A, De Rosa M, Zarrilli S, Lombardi G (2004) Outcome of cabergoline treatment in men with prolactinoma: effects of a 24-month treatment on prolactin levels, tumor mass, recovery of pituitary function, and semen analysis. J Clin Endocrinol Metab 89(4):17041711. https://doi.org/10.1210/jc.2003-030979

29. Fatemi N, Dusick JR, Mattozo C, McArthur DL, Cohan P, Boscardin J, Wang C, Swerdloff RS, Kelly DF (2008) Pituitary hormonal loss and recovery after transsphenoidal adenoma removal. Neurosurgery 63(4):709-718. https://doi.org/10.1227/01.Neu.00003 25725.77132.90 ((discussion 718-709)

30. Lobatto DJ, Steffens ANV, Zamanipoor Najafabadi AH, Andela CD, Pereira AM, van den Hout WB, Peul WC, Vliet Vlieland TPM, Biermasz NR, van Furth WR (2018) Work disability and its determinants in patients with pituitary tumor-related disease. Pituitary 21(6):593-604. https://doi.org/10.1007/s11102-018-0913-3

31. Erasmus University Rotterdam: Institute for Medical Technology Assessment: Questionnaires for the measurement of costs in economic evaluations. https://www.imta.nl/questionnaires/.

32. Andela CD, Scharloo M, Ramondt S, Tiemensma J, Husson O, Llahana S, Pereira AM, Kaptein AA, Kamminga NG, Biermasz NR (2016) The development and validation of the Leiden Bother and Needs Questionnaire for patients with pituitary disease: the LBNQ-Pituitary. Pituitary 19(3):293-302. https://doi.org/10.1007/ s11102-016-0707-4

33. Ware JE Jr, Sherbourne CD (1992) The MOS 36-item short-form health survey (SF-36). I. Conceptual framework and item selection. Med Care 30(6):473-483

34. Aaronson NK, Muller M, Cohen PD, Essink-Bot ML, Fekkes M, Sanderman R, Sprangers MA, te Velde A, Verrips E (1998) Translation, validation, and norming of the Dutch language version of the SF-36 Health Survey in community and chronic disease populations. J Clin Epidemiol 51(11):1055-1068. https://doi. org/10.1016/s0895-4356(98)00097-3

35. EuroQol Group (1990) EuroQol - a new facility for the measurement of health-related quality of life. Health Policy 16(3):199208. https://doi.org/10.1016/0168-8510(90)90421-9

36. Zhu D, Chung HF, Dobson AJ, Pandeya N, Giles GG, Bruinsma F, Brunner EJ, Kuh D, Hardy R, Avis NE, Gold EB, Derby CA, Matthews KA, Cade JE, Greenwood DC, Demakakos P, Brown DE, Sievert LL, Anderson D, Hayashi K, Lee JS, Mizunuma H, Tillin T, Simonsen MK, Adami HO, Weiderpass E, Mishra GD (2019) Age at natural menopause and risk of incident cardiovascular disease: a pooled analysis of individual patient data. Lancet Public Health 4(11):e553-e564. https://doi.org/10.1016/s2468 -2667(19)30155-0

37. Centraal Bureau voor de Statistiek: Standaard Onderwijsindeling 2016-Editie 2017/'18. In. Centraal Bureau voor de Statistiek, Den Haag/Heerlen, The Netherlands, (2018)

38. UNESCO Institute for Statistics: International Standard Classification of Education, Fields of education and training 2013 (ISCEDF 2013)—Detailed field descriptions. In. UNESCO Institute for Statistics, Montreal, Canada, (2015)

39. Zorginstituut Nederland: Richtlijn voor het uitvoeren van economische evaluaties in de gezondheidszorg. In. Zorginstituut Nederland, Diemen, The Netherlands, (2016)
40. Organisation for Economic Co-operation and Development: Purchasing power parities (PPP). https://data.oecd.org/conversion/ purchasing-power-parities-ppp.htm (2019).

41. Shrier I, Platt RW (2008) Reducing bias through directed acyclic graphs. BMC Med Res Methodol 8:70. https://doi. org/10.1186/1471-2288-8-70

42. Martínez-Momblán MA, Gómez C, Santos A, Porta N, Esteve J, Úbeda I, Halperin I, Campillo B, Guillaumet M, Webb SM, Resmini E (2016) A specific nursing educational program in patients with Cushing's syndrome. Endocrine 53(1):199-209. https://doi.org/10.1007/s12020-015-0737-0

43. Haugland T, Veenstra M, Vatn MH, Wahl AK (2013) Improvement in stress, general self-efficacy, and health related quality of life following patient education for patients with neuroendocrine tumors: a pilot study. Nurs Res Pract 2013:695820. https://doi. org/10.1155/2013/695820

44. Andela CD, Repping-Wuts H, Stikkelbroeck N, Pronk MC, Tiemensma J, Hermus AR, Kaptein AA, Pereira AM, Kamminga NGA, Biermasz NR (2017) Enhanced self-efficacy after a selfmanagement programme in pituitary disease: a randomized controlled trial. Eur J Endocrinol 177(1):59-72. https://doi. org/10.1530/eje-16-1015

45. Hatipoglu E, Topsakal N, Atilgan OE, Alcalar N, Camliguney AF, Niyazoglu M, Cotuk HB, Kadioglu P (2014) Impact of exercise on quality of life and body-self perception of patients with acromegaly. Pituitary 17(1):38-43. https://doi.org/10.1007/s1110 2-013-0463-7

46. Lima TRL, Kasuki L, Gadelha MR, Lopes AJ (2019) The effectiveness of a therapist-oriented home rehabilitation program for a patient with acromegaly: a case study. J Bodyw Mov Ther 23(3):634-642. https://doi.org/10.1016/j.jbmt.2019.01.006

47. Papanicolas I, Woskie LR, Jha AK (2018) Health care spending in the United States and other high-income countries. JAMA 319(10):1024-1039. https://doi.org/10.1001/jama.2018.1150

48. Groenewegen P (2016) General practitioners as gatekeepers: Better health care than in countries with self-referral to specialists? Ned Tijdschr Geneeskd 160:D88

49. Velasco Garrido M, Zentner A, Busse R (2011) The effects of gatekeeping: a systematic review of the literature. Scand J Prim Health Care 29(1):28-38. https://doi.org/10.3109/02813 432.2010.537015

50. Rijksinstituut voor Volksgezondheid en Milieu (RIVM): Kosten van ziekten 2017. https://statline.rivm.nl/\#/RIVM/nl/datas et $/ 50050 \mathrm{NED} /$ table?ts=1592149193432 (2019).

51. Centraal Bureau voor de Statistiek: Gezondheid en zorggebruik; persoonskenmerken. https://opendata.cbs.nl/statline/\#/CBS/nl/ dataset/83005NED/table?ts=1592073580866 (2020).

52. Macotela Y, Triebel J, Clapp C (2020) Time for a new perspective on prolactin in metabolism. Trends Endocrinol Metab 31(4):276286. https://doi.org/10.1016/j.tem.2020.01.004

53. van Lier LI, Bosmans JE, van Hout HPJ, Mokkink LB, van den Hout WB, de Wit GA, Dirksen CD, Nies H, Hertogh C, van der Roest HG (2018) Consensus-based cross-European recommendations for the identification, measurement and valuation of costs in health economic evaluations: a European Delphi study. Eur J Health Econ 19(7):993-1008. https://doi.org/10.1007/s1019 8-017-0947-x

54. Xuan J, Kirchdoerfer LJ, Boyer JG, Norwood GJ (1999) Effects of comorbidity on health-related quality-of-life scores: an analysis of clinical trial data. Clin Ther 21(2):383-403. https://doi. org/10.1016/s0149-2918(00)88295-8

Publisher's Note Springer Nature remains neutral with regard to jurisdictional claims in published maps and institutional affiliations. 